\title{
Escherichia coli infection induces mucosal damage and expression of proteins promoting urinary stone formation
}

\author{
T. Djojodimedjo • D. M. Soebadi $\cdot$ Soetjipto
}

Received: 1 January 2013/Accepted: 25 May 2013/Published online: 12 June 2013

(C) Springer-Verlag Berlin Heidelberg 2013

\begin{abstract}
The effect of urinary tract infection (UTI) on mucosal damage and production of proteins promoting urinary stone formation has not been elucidated. Osteopontin production, with associated mucosal damage due to UTI, may allow easier crystal retention and nucleation resulting in stone formation. The aim of this study is to demonstrate that expression of osteopontin (OPN), OPN mRNA, TLR-4, JNK, TNFR-1, iNOS, HMGB-1, and apoptosis process is higher than normal at renal tubular cells due to urinary tract infection by Escherichia coli. Adult male New Zealand strain rabbits were used. Thirty New Zealand strain rabbits were divided into three groups. The first group acted as controls, the second group underwent ligation of right ureter, and the third group underwent ligation of right ureter and injection of Escherichia coli $105 / \mathrm{ml}$ proximal to ligation. Nephrectomy and histological examination were performed after 5 days. All groups were HE stained to examine mucosal damage, specific monoclonal antibodies for TLR-4, JNK, mRNA OPN, OPN, TNFR-1, iNOS and HMGB-1. Apoptotic nuclei were demonstrated using TUNEL method. Statistical calculations were performed using ANOVA test, with $p<0.05$
\end{abstract}

\footnotetext{
T. Djojodimedjo $(\bowtie) \cdot$ D. M. Soebadi

Department of Urology, Airlangga University School of

Medicine, Dr. Soetomo Hospital, Jln Moestopo No. 6-8,

Surabaya 60286, East Java, Indonesia

e-mail: aniesshahab@yahoo.com

D. M. Soebadi

e-mail: dmsoebadi@yahoo.com

\section{Soetjipto}

Department of Biochemistry, Airlangga University School of

Medicine, Jln. Moestopo No. 47, Surabaya 60286,

East Java, Indonesia

e-mail: jtbrsoetjipto@hotmail.com
}

considered significant. The findings confirmed the hypothesis that infection of urinary tract by Escherichia coli demonstrated higher expression of OPN, OPN mRNA, TLR-4, JNK, TNFR-1, iNOS, HMGB-1, apoptosis process and mucosal damage than normal. Infection of urinary tract by Escherichia coli caused higher than normal expression of promoter protein osteopontin and mucosal damage at renal tubular cells. These suggest that urinary infection may promote stone formation by mucosal damage and elevate promoter protein osteopontin at tubulus cell, allowing easier crystal retention and nucleation.

Keywords Urinary tract infection · Osteopontin . Apoptosis $\cdot$ Necrosis $\cdot$ Stone formation

\section{Introduction}

Urinary tract lithiasis is a prevalent problem since early history of mankind [1]. Epidemiological surveys have shown in economically developed countries including Indonesia; the prevalence of urolithiasis ranged between 4 and $20 \%$ [2]. The etiology of kidney stone is multifactorial. It includes both intrinsic factors such as demographic, anatomic and genetic aspects, as well as extrinsic factors such as geographic predilection, climate, lifestyle pattern and dietary habits. Yet there are many unexplained facts, including why not all individuals with similar risk factors form stones, why most stones are unilateral while conditions are similar on both sides. Understanding how the stone forms in vivo may lead to preventive measures [3].

Many proteins are involved in urinary stone formation. These proteins may be detected by analysis of stone nucleus matrix, or detection in urine samples. Presence of these proteins is assumed to play an important role in 
formation of stones, both as promoters and inhibitors in each phase of stone formation. Proteins considered as promoters include osteopontin (OPN), albumin, and CD 44. In a cell culture model, Verhulst et al. suggested that these may play a crucial role in the process of crystal retention. Inhibitor proteins include inter- $\alpha$ inhibitor, bikunin, heparan sulfate, and fibronectin $[4,5]$.

Many urinary tract stones are found with synchronous urinary tract infection. Relationship between urinary tract infection and urinary lithiasis is currently understood both as cause and complication. As a possible cause for stone formation, infection induces chemical changes within the urinary tract, thus allowing formation of crystals within the urinary tract. Inflammation may lead to production of proinflammatory substances such as osteopontin and other matrix proteins. Escherichia coli infection increases this protein which then acts as a chemoattractant and has the role of crystal nidation, thus leading to stone formation. Inflammation may also induce urothelial necrosis and apoptosis.

In our hospital, the most common cause of urinary tract infection (UTI) is E. coli infection, counts for at least $40 \%$ case. Interaction between lipopolysaccharide (LPS) from E. coli with toll-like receptor (TLR4) of the cell wall may increase reactive oxygen species (ROS) and nitric oxide (NO) and subsequently activate protein-1/c-Jun $\mathrm{N}$ terminal kinase (AP-1/JNK) through protein kinase-C (PKC). This substance will induce OPN transcription through mRNA and tumor necrosis factor- $\alpha(\mathrm{TNF}-\alpha)$. Free radicals resulted from this infection will induce cell necrosis and tissue damage. In other way, TNF- $\alpha$ will bind to tumor necrosis factor receptor-1 (TNFR-1) in cell membrane and lead to apoptosis. This combination will finally damage renal epithelium [6].

Association between mucosal damage and stone formation has been widely known. Urothelial damage is considered to be associated with stone-forming crystals. Mucosal damage is also responsible to activate several proteins including stone-forming modulator [7]. Therefore, increase of stone-forming proteins due to UTI is predicted as a catalyst of crystal nidation which subsequently facilitates stone formation [8]. Based on the data, we analyse mucosal damage and increase of stone-forming protein due to $E$. coli UTI.

\section{Materials and methods}

Male New Zealand strain rabbits aged 5-6 months were housed in the animal resources facility at our institution with 1-week adaptation period. A total of 3 groups of 10 rabbits each were examined. One group underwent nephrectomy only after 5 days. A second group underwent ureteral ligation and nephrectomy at 5 days. A third group underwent ureteral ligation, injection of E. coli 10 [5] colony-forming units per milliliter $(\mathrm{CFU} / \mathrm{ml})$ and nephrectomy at 5 days. Ureteral ligation was performed by a flank incision under ketamine $30 \mathrm{mg} / \mathrm{kg}$ anesthesia. All procedures adhered to principles of sterility. Ethical clearance from the Animal Research Ethics Committee of our institution was obtained.

Nephrectomy and histological examination were performed after 5 days. Kidney specimens from all groups were HE stained to examine mucosal damage. Specific monoclonal antibodies were used to demonstrate OPN, TLR-4, JNK, TNFR-1, iNOS and HMGB-1. Apoptotic nuclei were demonstrated using TUNEL method. Chromogenic in situ hybridization (CISH) for examination of osteopontin mRNA was performed. One-way ANOVA was used to analyze the effect of ureteral ligation and $E$. coli injection. Differences were considered significant when $p<0.05$. All tests were conducted using commercially available statistical analysis software.

\section{Results}

During the study period, three subjects died. Specimens were taken from the remaining 27 subjects, distributed 10 in control group (A), 9 in ureter ligation group (B), and 8 in ureter ligation and $E$. coli injection group $(\mathrm{C})$. Rabbits used weighed about 155-190 g. There were no weight differences between groups (one-way ANOVA, $F=0.043$, $p=0.958)$. All study parameters were significantly different in group $\mathrm{C}$ compared to the other groups. Using Pizem and Cor technique, means of all study parameters are shown in Table 1. Data distribution with KolmogorovSmirnov among groups showed homogenous variance in all parameters as shown in Fig. 1.

Meanwhile, HE staining showed difference among groups. No cell damage was observed in control group specimens, whereas a significant cell damage was easily visible in intervention group using $400 \times$ microscope magnification as shown in Fig. 2.

\section{Discussion}

Ureteric obstruction by ligation allowed retention of bacteria within renal pelvicalyceal system. Urinary tract obstruction is a known risk factor for urinary tract infection. Escherichia coli concentration used was $10^{5} \mathrm{CFU} / \mathrm{ml}$ which is considered as a significant concentration to cause infection [9]. A preliminary study has shown that significant histopathological changes were observed at least 5 days after bacterial injection. The frequency of UTI 
among urolithiasis patients was $42 \%$ which was greater than that of non-urolithiasis patients. Escherichia coli was the predominant pathogen associated mostly with non infection stone [10]. We have carried out a series of attempts concerning the UTI and its predisposing factors particularly the intrinsic types as well as environmental

Table 1 Statistical analysis of each study parameter

\begin{tabular}{|c|c|c|c|c|c|}
\hline & Group & $\begin{array}{l}\text { Mean } \\
\sum / 1 \mathrm{p}\end{array}$ & $\begin{array}{l} \pm \\
\mathrm{SD}\end{array}$ & Notation & $\begin{array}{l}\text { One-way } \\
\text { ANOVA }\end{array}$ \\
\hline \multirow[t]{3}{*}{ TLR-4 } & A & 6.22 & 2.386 & A & \multirow{3}{*}{$\begin{array}{c}F=70.709 \\
p=0.000\end{array}$} \\
\hline & B & 7.44 & 1.810 & A & \\
\hline & $\mathrm{C}$ & 22.33 & 8.072 & B & \\
\hline \multirow[t]{3}{*}{ JNK } & A & 2.00 & 1.00 & $\mathrm{~A}$ & \multirow{3}{*}{$\begin{array}{l}F=68.362 ; \\
p=0.000\end{array}$} \\
\hline & B & 3.00 & 2.121 & A & \\
\hline & $\mathrm{C}$ & 14.78 & 3.801 & B & \\
\hline \multirow[t]{3}{*}{ TNFR-1 } & $\mathrm{A}$ & 12.67 & 3.354 & A & \multirow{3}{*}{$\begin{array}{c}F=33.234 \\
p=0.000\end{array}$} \\
\hline & B & 13.56 & 2.744 & A & \\
\hline & $\mathrm{C}$ & 23.78 & 3.492 & B & \\
\hline \multirow[t]{3}{*}{ iNOS } & A & 2.00 & 1.225 & A & \multirow{3}{*}{$\begin{array}{c}F=89.112 ; \\
p=0.000\end{array}$} \\
\hline & B & 3.11 & 2.088 & A & \\
\hline & $\mathrm{C}$ & 16.56 & 3.492 & B & \\
\hline \multirow{3}{*}{$\begin{array}{l}\text { mRNA } \\
\text { Osteopontin }\end{array}$} & $\mathrm{A}$ & 6.22 & 2.224 & A & \multirow{3}{*}{$\begin{array}{c}F=24.005 ; \\
p=0.000\end{array}$} \\
\hline & B & 5.67 & 1.581 & A & \\
\hline & $\mathrm{C}$ & 13.67 & 3.873 & B & \\
\hline \multirow[t]{3}{*}{ OPN } & A & 11.78 & 2.386 & A & \multirow{3}{*}{$\begin{array}{c}F=16.672 ; \\
p=0.000\end{array}$} \\
\hline & B & 7.44 & 1.810 & A & \\
\hline & $\mathrm{C}$ & 22.33 & 8.072 & B & \\
\hline \multirow[t]{3}{*}{ HMGB-1 } & $\mathrm{A}$ & 7.11 & 2.472 & A & \multirow{3}{*}{$\begin{array}{c}F=12.483 \\
p=0.000\end{array}$} \\
\hline & B & 11.22 & 4.206 & A & \\
\hline & $\mathrm{C}$ & 16.00 & 4.359 & B & \\
\hline \multirow[t]{3}{*}{ TUNEL } & A & 7.56 & 2.744 & A & \multirow{3}{*}{$\begin{array}{c}F=18.825 \\
p=0.000\end{array}$} \\
\hline & B & 7.67 & 2.550 & A & \\
\hline & $\mathrm{C}$ & 15.67 & 4.123 & B & \\
\hline
\end{tabular}

parameters related to the subject as the UTI elevated in the last years in Indonesia. Due to the high number of $E$. coli infection, we assume the existence of a relationship between $E$. coli infection and urinary stone disease. The use of $E$. coli in this study is purely based on the fact that most stone former patients in Indonesia come with an E. coli positive urine culture.

Basavaraj et al. [5] explain the role of OPN as an inhibitory protein to calcium stone. Despite the relevant studies, there are some data suggest that OPN may have a dual role, both inhibit and promote stone. Although OPN generally reduced the binding of urinary calcium oxalate dehydrate crystals to canine's kidney cells, at times it also appeared to mediate adhesion. It is possible therefore that OPN can reduce or increase crystal binding. A study by Thurgood et al. [11] represents this net effect of its opposing inhibitory or promotery properties. A single base mutation in the OPN gene is also seen at significantly higher incidence in patients with recurrent stone formation or familial nephrolithiasis, as demonstrated by Yamate et al. [12] in 2000. Osteopontin is involved in stabilizing the hyaluronic acid layer that may be involved in crystal adhesion and acts as a promoter. The understanding of the role of stone promoters, such as OPN, GAGs and CD 44 has improved rapidly and may result in more effective ways in clinical application. From previous studies [5, 13], the role of inhibitory OPN was demonstrated in urine; while in this study, we analyzed the expression of OPN in the cell, which is considered to be the stone promoter.

Significant OPN expression and duration of infection depends on inflammation severity, while inflammation itself depends on virulence and host resistance. Interaction between bacterial LPS and TLR-4 acts as a natural immune response to antigen. Activation of TLR-4 results in release of other pro-inflammatory substances since TLR-4 is a control center of signal transduction, including free radical
Fig. 1 Expression of study parameters among groups

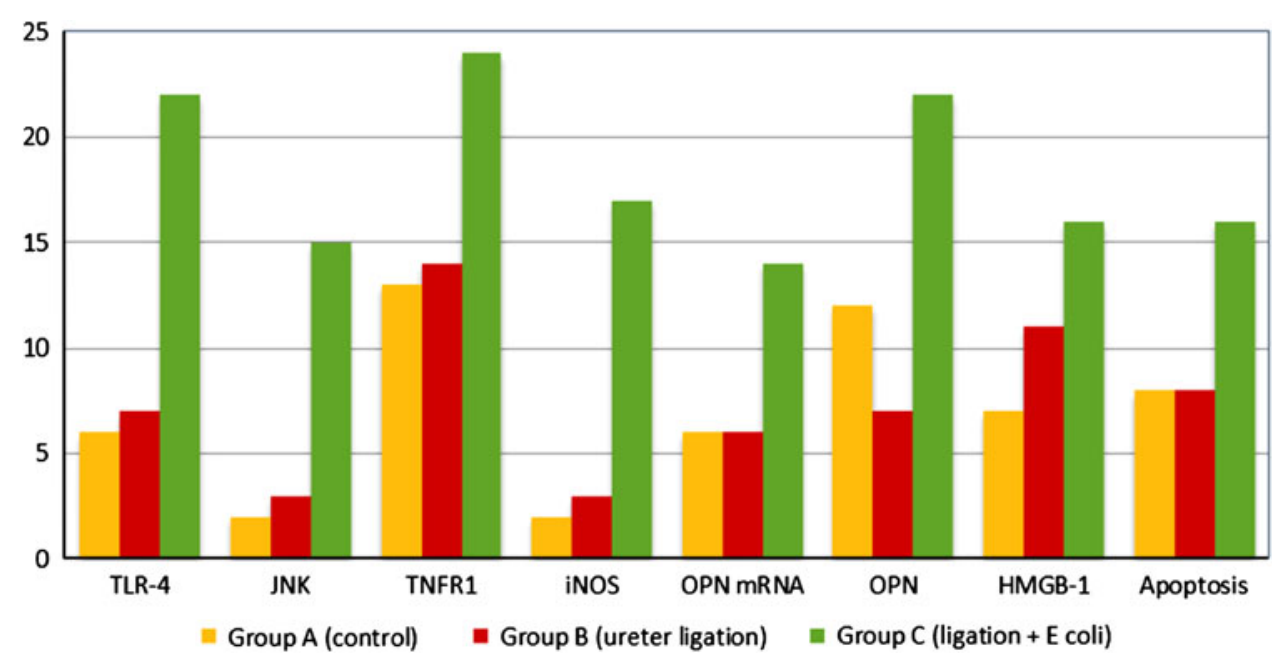


Fig. 2 Intraureteral E. coli induction increases expression of each study parameter in renal tubular epithelial cells. Positive expressions are shown in black arrow (I-VIII). HE staining also shows tubular area damage higher in group C (IX)
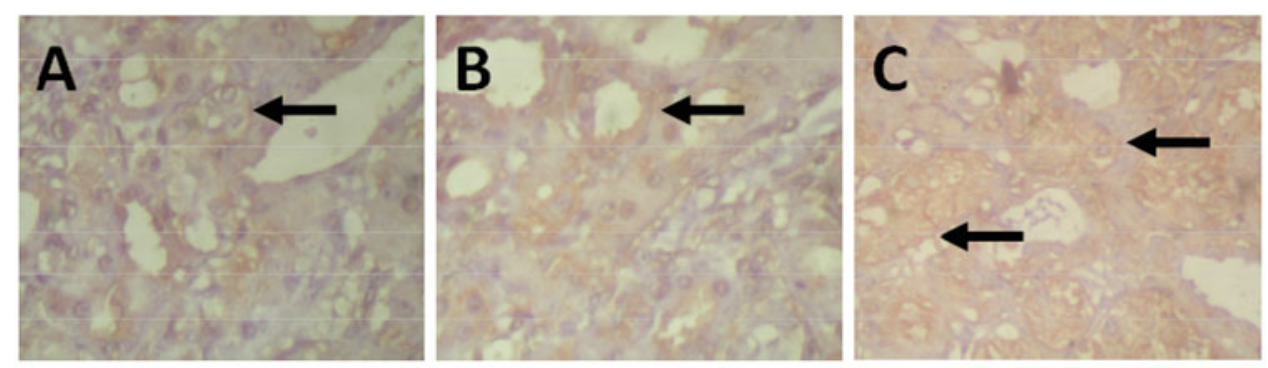

\section{TLR-4 Expression}
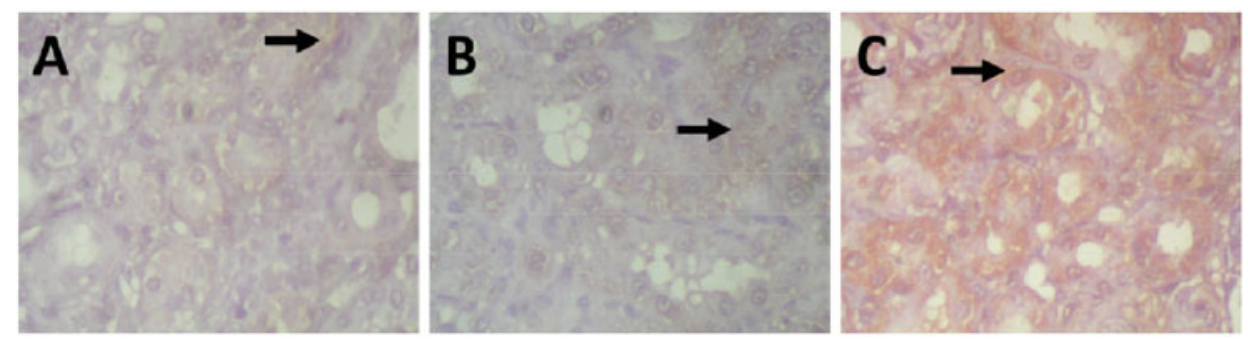

\section{JNK Expression}
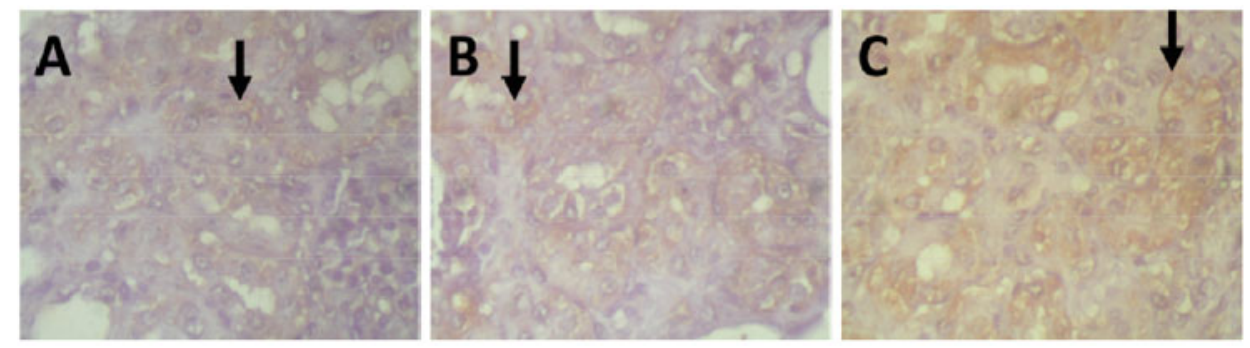

\section{Osteopontin mRNA Expression}
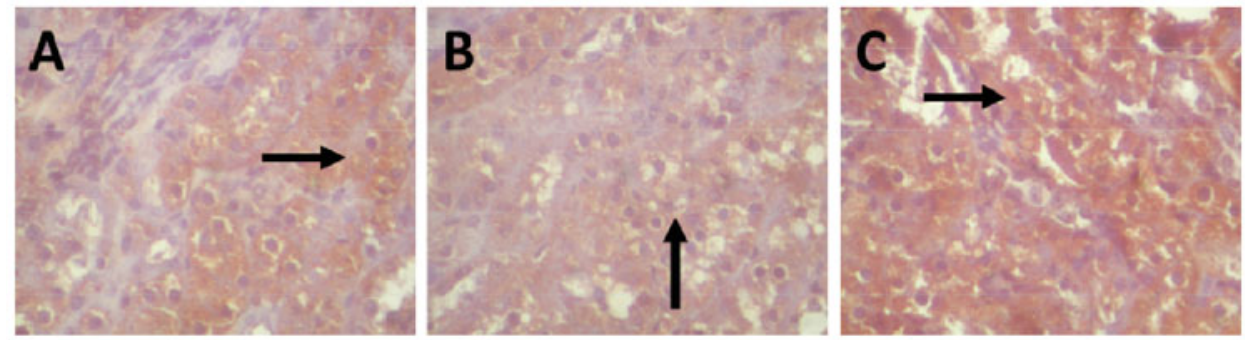

IV. Osteopontin Protein Expression
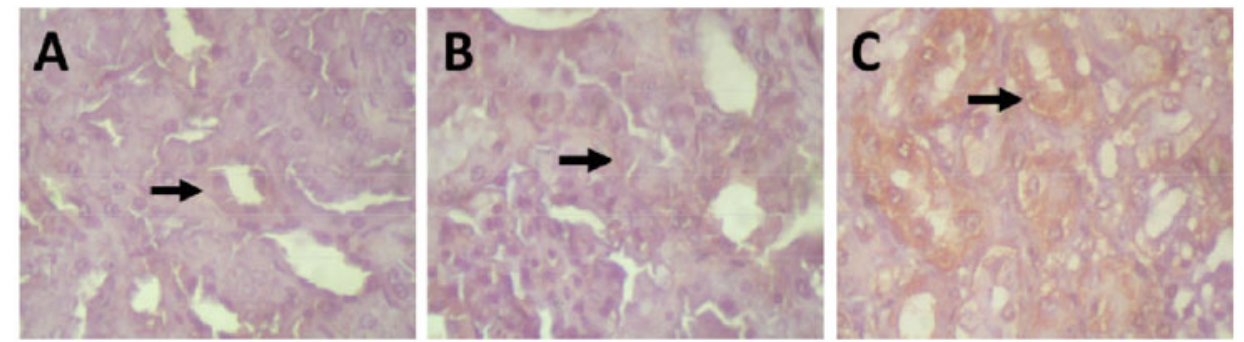

V. TNFR1 Protein Expression 
Fig. 2 continued
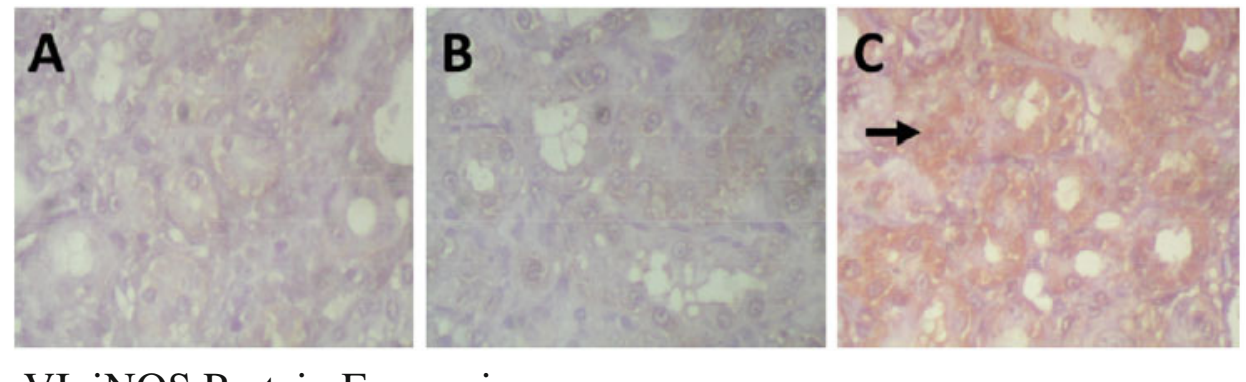

VI. iNOS Protein Expression
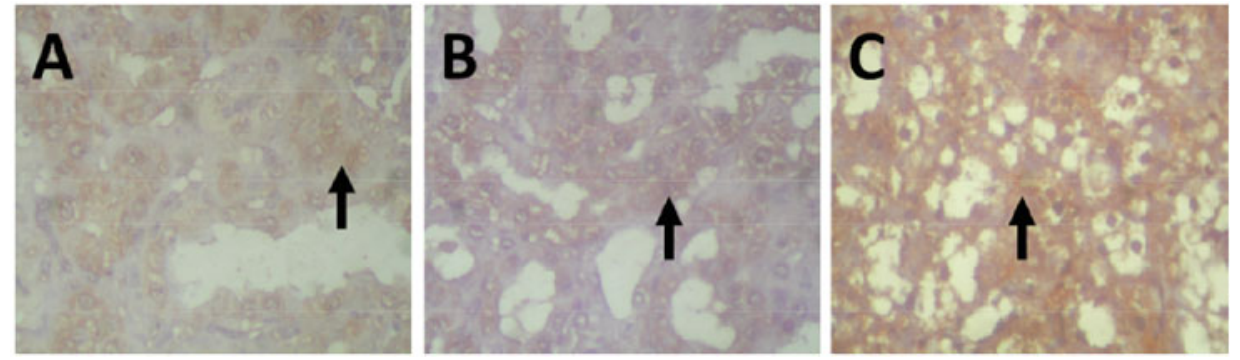

\section{HMGB-1 Expression}
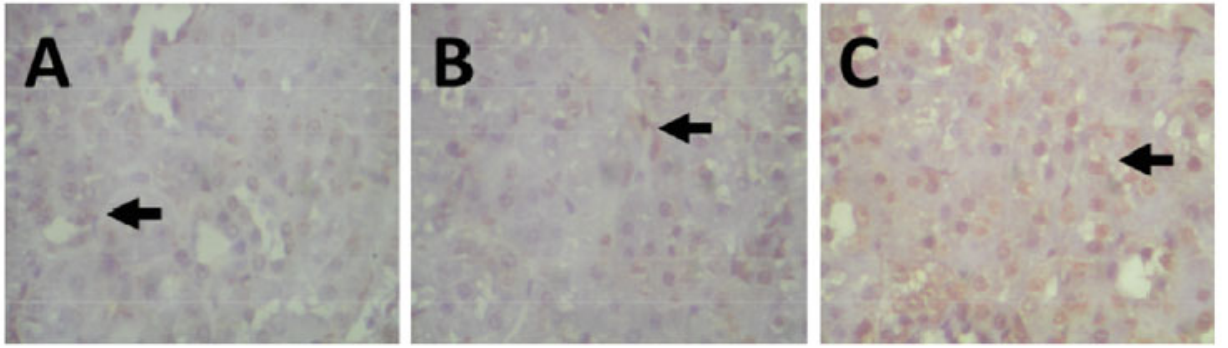

VIII. DNA Fragmentation (TUNEL)
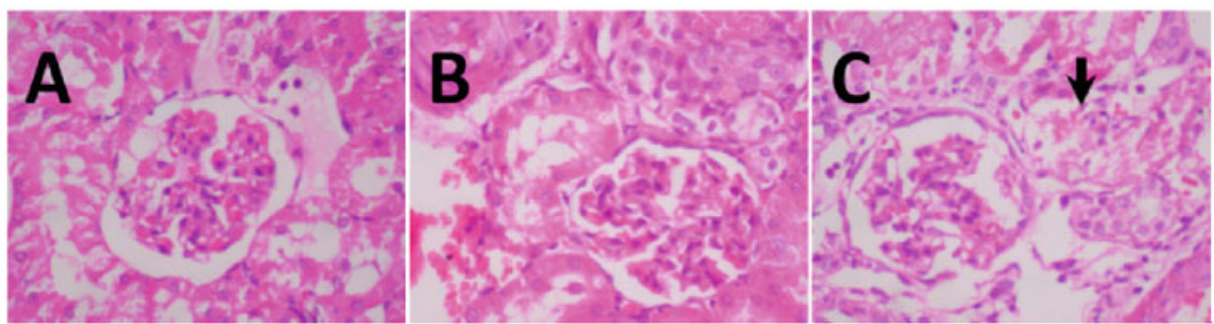

\section{HE Staining}

activation such as $\mathrm{O}^{2-}$ and hydrogen peroxide $\left(\mathrm{H}_{2} \mathrm{O}_{2}\right)$, known as ROS [14]. We found TLR-4 expression much higher in group $\mathrm{C}(F=70.709 ; p=0.000)$.

ROS enhances c-Jun Nitrite-terminal Kinase (JNK) activation. JNK will activate several protein transcription in the cell nucleus, such as OPN and TNF- $\alpha$. Initially, JNK will activate mRNA osteopontin and then increase OPN transcription. We found that JNK expression was significantly higher in interventional group compared to control $(F=68.362 ; p=0.000)$. The study also demonstrates both mRNA osteopontin and OPN itself higher in group C. This is important as high level of OPN expression is produced by the cell itself due to infection. Osteopontin and osteopontin mRNA were significantly different between control and intervention groups $(F=16.672 ; p=0.000$ and $F=24.005 ; p=0.000$, respectively). There was inconsistent result as we revealed mRNA expression in group B is lower than control, though it is not significant. Meanwhile OPN expression in group B is higher than control. Despite the fact that we analysed in a single period 
of time and mRNA osteopontin is already transformed into osteopontin, mRNA osteopontin may deliver more than one osteopontin.

TNF- $\alpha$ could also be activated by JNK. The increase of TLR-4 and TNF- $\alpha$ expression will stimulate inducible nitric oxide synthase (iNOS) and result in $\mathrm{NO}^{-}$release and cell necrosis. High mobility group box-1 (HMGB-1) will then be produced by necrotic cell. Therefore, increase of HMGB-1 will reflect cell necrosis [15]. We found iNOS and HMGB-1 expression in group $\mathrm{C}$ much higher than control (iNOS; $F=89.112, \quad p=0.000 ;$ HMGB-1, $F=12.483, p=0.000)$. It proves that $E$. coli UTI in rabbit causes necrosis of the renal tubular epithelium. TNF$\alpha$ and TNFR-1 will activate mitogen activated protein kinase (MAPK) pathway and subsequently caspase- 8 and caspase-3 as apoptosis effector. This pathway resulted in apoptosis and is visible as fragmented DNA using TUNEL assay [15]. We found fragmented DNA much higher in intervention group. We also demonstrate significantly higher necrosis and apoptosis in group $\mathrm{C}$.

Urinary tract mucosa as well as epithelium react to infection through two phases, recognize bacteria through its virulence factor and continue with signal process via TLRs [14]. Lipopolysaccharide, as a virulence factor of Gram-negative bacteria including E. coli, activates cell through TLR-4 pathway. This molecule is recognized with LPS binding protein (LBP), CD 14, and MD-2. Meanwhile, epithelium constitutes first defense line against infection. Therefore, it is not astonishing that many TLRs are found in epithelium. Inflammation to the kidney will trigger TLR4 expression that are critical for host defense [16]. We found different level of TLR-4 expression among three groups. Groups A and B showed no significant increase, while group $\mathrm{C}$ showed significant increase.

Interaction between LPS and TLR-4 on the surface of epithelium brings signal transduction including ROS. In normal circumstances, ROS is produced by nicotinamide adenine dinucleotide phosphate (NADH) oxidase. As we know, infected cell needs more oxygen via oxidative reaction to kill bacteria and resulted in excalation of ROS. These free radicals will then activate several signal molecule like protein kinase-C (PKC), JNK, MAPK and extracellular signal regulated kinase (ERK1/2). We found that JNK expression for groups A and B was not significantly different. Meanwhile in group C, JNK was highly increased. JNK/AP-1 will then activate fibronectin, OPN, monocyte chemoattractant protein-1 (MCP-1), bikunin and $\alpha$-microglobulin ( $\alpha$-1 M) [15]. We also found significant excalation for both mRNA OPN and OPN in group C. It demonstrates that UTI induces OPN expression and this is consistent with previous study that OPN expression increased due to lesion or inflammation of the epithelium [17].
In acute inflammation, TNF- $\alpha$ acts as a proinflammatory cytokine and chemoattractant. Excessive amount of this cytokine often causes severe clinical condition such as sepsis, shock, and autoimmune diseases like rheumatoid arthritis, ankylosing spondylitis, Crohn's disease and psoriasis. As a signaling molecule, TNF- $\alpha$ has two receptors: the TNFR-1 and TNFR-2. TNFR-1 is widely available in tissue and plays more role than the TNFR-2 [18, 19].

In this study, expression of TNF- $\alpha$ and TNFR-1 in groups A and B did not increase as in group C. This suggests that UTI increased the expression of TNF- $\alpha$ and TNFR-1. In addition, LPS and TLR-4 binding will also induce iNOS through activation of macrophages. Free radicals due to inflammatory and infectious conditions have toxic cellular effects [20].

Our study revealed significant increase of iNOS in group C compared to others. This suggests that urinary tract infection increases the expression of iNOS. As mentioned earlier, interaction between LPS and TLR-4 has triggered a variety of signal transduction. Because some of these substances are also chemoattractants, other substances such as monocytes and macrophages will also be mobilized to the area [21].

The end result of these processes is cell damage or necrosis. Rupture of the cell wall will release the contents or organelles within the cell to the intercellular and result in an inflammatory reaction [22]. The cell will also release existing HMGB. There are three types of HMGB. Of these three types, HMGB-1 is the most numerous in the body. On the condition of necrosis, HMGB-1 is passively released because of cell rupture, while in the inflammatory process, HMGB-1 is actively released by macrophages and monocytes. Furthermore, outside the cell this protein will serve as a proinflammatory agent [23].

In this study, there were no differences in the expression of HMGB-1 in groups A and B as a control group and the control group treatment. In group c, there is an increased expression of HMGB-1, and significantly different compared to the control group. This suggests that urinary tract infection occured in epithelial cell damage in the form of necrosis. In contrast to necrosis, apoptosis does not occur at cell rupture. So there is no content or organelles within the cell released intracellularly. That is why inflammatory process does not occur in apoptosis. Under normal circumstances, apoptosis is a physiological process that plays an important role in the growth and development. However, in certain circumstances, for example, tissue lesion on the epithelium, the apoptosis process will increase and become not physiologic anymore [23]. Significant differences in the incidence of apoptosis between control group and treatment group in this study are clear. These findings support the assumption that UTI damages cells through apoptosis. Renal tubular 
epithelial cell damage eases stone-forming crystals attachment, resulting in nucleation [24].

These results clearly prove that UTI causes damage to renal tubular epithelial cells, either due to necrosis or apoptosis. This damage eventually resulted in mucosal defects. On the other hand, the inflammatory reaction due to infection has also been shown to activate various signaling pathways of immune response. Presence of mucosal damage and promoter proteins in renal tubular epithelium due to UTI will ease crystal stones attachment and facilitate nidus stone formation. Therefore, the effect of UTI on the incidence of urinary tract stones may occur this way. Limitations of this study are not yet proven that the existence of OPN and damage in renal tubular epithelial cells were also followed by an increase in attachment of stone crystals in the tubular epithelium, as the beginning of stone formation. The use of $E$. coli instead of Pseudomonas, Proteus, Klebsiella, etc., can make a drawback of the study because these bacteria are able to make a more complicated UTI and theoretically tend to form a urinary stone. Another limitation is we did not perform urine culture examination at the end of the study. The number of injected bacteria in the urinary tract does not represent the actual number of bacteria in the urinary tract as E.coli can subsequently multiply or even die. However, the data are clinically meaningful and of interest to those facing the challenge of how to best understand the stone formation.

\section{Conclusion}

Based on the results, we found that $E$. coli infection in a rabbit model is associated with significantly increased expression of TLR-4, JNK, mRNA OPN and OPN in renal tubular epithelium. Expression of iNOS, TNFR-1, HMGB1 , and DNA fragmentation in renal tubular epithelium is also found higher compared to controls. Renal tubular epithelial cell damage was proven higher than control. Thus, UTI due to E. coli causes expression of OPN and damage in renal tubular epithelial cells. Therefore, the risk of urinary tract stones in UTI is higher.

\section{Conflict of interest None}

\section{References}

1. Lopez M, Hoppe B (2010) History, epidemiology and regional diversities of urolithiasis. Pediatr Nephrol 25:49-59

2. Trinchieri A (2008) Epidemiology of urolithiasis : an update. Clin Cases Miner Bone Metab 5(2):101-106

3. Tosukhowong P et al (2007) Crystalline composition and etiologic factors of kidney stone in Thailand : update 2007. Asian Biomed 1(1):87-95
4. Verkoelen CF (2006) Crystal retention in renal stone disease: a crucial role for the glycosaminoglycan hyaluronan? J Am Soc Nephrol 17:1673-1687

5. Basavaraj DR (2007) The role of urinary kidney stone inhibitors and promoters in the pathogenesis of calcium containing renal stones. EAU-EBU update series 5:126-136

6. Klump DJ, Schaeffer AJ (2010) Induction and modulation of host responses by uropathogenic Escherichia coli structures. Urogenital Infections 2010. Arnhem, The Netherlands, VEAUICUD: pp 35-41

7. Evan AP (2010) Physiopathology and etiology of stone formation in the kidney and the urinary tract. Pediatr Nephrol 25:831-841

8. Hall PM (2009) Nephrolithiasis:treatment, causes, and prevention. Clevel Clin J Med 76(10):583-591

9. Kwon JH et al (2012) Impact of laboratory-reported urine culture colony counts on the diagnosis and treatment of urinary tract infection for hospitalized patients. Am J Clin Pathol 137:778-784

10. Al-Jebouri MM, Atalah N (2012) A study on the interrelationship between renal calculi, hormonal abnormalities and urinary tract infections in iraqi patients. Open J Urol 2:6-10

11. Thurgood Lauren A, Sørensen Esben S, Ryall Rosemary L (2012) The effect of intracrystalline and surface-bound osteopontin on the attachment of calcium oxalate dihydrate crystals to MadinDarby canine kidney (MDCK) cells in ultrafiltered human urine. BJU Intern 109(7):1100-1109

12. Yamate T, Tsuji H, Amasaki N et al (2000) Analysis of osteopontin DNA in patients with urolithiasis. Urol Res 28:159-166

13. Wesson JA, Johnson RJ, Mazzali M et al (2003) Osteopontin is a critical inhibitor of calcium oxalate crystal formation and retention in renal tubules. J Am Soc Nephrol 14:139-147

14. Wullt B et al (2010) Immunity, genetic and susceptibility to urinary tract infection. Urogenital Infections 2010. Arnhem, The Netherlands, VEAU-ICUD: pp 23-31

15. Nelson KK et al (2006) Redox-dependent matrix metalloproteinase-1 expression is regulated by JNK through Ets and AP-1 promoter motifs. J Biol Chem 281(20):14100-14110

16. Hartwig WB, Wolfgang GB (2010) Immunology of the urinary tract. Urogenital Infections 2010. Germany, European Association of Urology, International Consultation on Urological Diseases: pp 42-56

17. Asselman M, Verhulst A, De Broe ME, Verkoelen CF (2003) Calcium oxalate crystal adherence to hyaluronan-, osteopontin-, and CD44-expressing injured/regenerating tubular epithelial cells in rat kidneys. J Am Soc Nephrol 14(12):3155-3166

18. Good DW, George T, Watts BA (2009) Lipopolysaccharide directly alters renal tubule transport through distinct TLR4dependent pathways in basolateral and apical membranes. Am J Physiol Renal Physiol 297:866-874

19. Khan $\mathrm{Fa}$, Khan MF (2010) Inflammation and acute phase response. Intern J Appl Biol Pharm Tech 1(2):312-321

20. Yang X, Zhao Y, Wang H, Mei Q (2007) Macrophage activation by an acidic polysaccharide isolated from Angelica sinensis (Oliv.) Diels. J Biochem Mol Biol 40(5):636-643

21. Cirl C et al (2008) Subversion of toll-like receptor signaling by a unique family of bacterial Toll/interleukin-1 receptor domaincontaining proteins. Nat Med 14(4):399-406

22. Pollard TD, Earnshaw WC (2008) Programmed cell death. Cell biology. Saunders Elsevier, Philadelphia, pp 833-850

23. Orlova VV et al (2007) A novel pathway of HMGB1-mediated inflammatory cell recruitment that requires Mac-1-integrin. EMBO J 26:1129-1139

24. Khan SR (2004) Crystal-induced inflammation of the kidneys: results from human studies, animal models, and tissue-culture studies. Clin Exp Nephrol 8(2):75-88 